Journal of Chemical Engineering and Materials Science Vol. 4(2), pp. 23-31, February 2013

Available online at http://www.academicjournals.org/JCEMS

DOI: $10.5897 / J C E M S 12.027$

ISSN 2141-6605 @2013 Academic Journals

Full Length Research Paper

\title{
Synthesis of branched fatty esters from Sterculia oil
}

\author{
Yoel Pasae \\ Chemical Engineering Department, Christian University of Indonesia Paulus Makassar, Indonesia. E-mail: \\ ypasae@yahoo.com.Tel: +62 411 582825. Fax: +62 411582825. \\ Accepted 19 December, 2012
}

\begin{abstract}
Biodiesel produced from vegetable oils are triglyceride. Their composition is generally of a straightchain fatty acid length. The existence of long straight-chain fatty acids in triglycerides affects the physical and chemical properties of biodiesel. Problems associated with the use of biodiesel up to now are the high pour point and NOx emissions which are higher than that of diesel fuel. There are two physical properties of biodiesel which is still an issue until now- the high pour point and NOx emissions resulting from the combustion. This resulted from the use of biodiesel which is blended with petroleum diesel. To overcome this problem, additives are required. In order to be compatible with biodiesel and not give a large negative impact on the environment, the expected additive for biodiesel was also made from vegetable oil, likes branched fatty esters. Preparation of branched fatty esters in this study aimed to produce branched fatty ester from sterculia oil through the four stages of the process, namely: extraction, first transesterification, hydrogenation and second transesterification. The results of the analysis show that the branched fatty esters produced in this research contain $\mathrm{C}_{22} \mathrm{H}_{44} \mathrm{O}_{2}$ with molecular weight of $340 \mathrm{~g} / \mathrm{mol}$, whose existence in the form of a mixture with other branched esters with specific gravity at $40^{\circ} \mathrm{C}$ is 0.870 , kinematic viscosity $5.907 \mathrm{St}$, iodine number $16.25 \mathrm{~g} \mathrm{I}_{2} / 100 \mathrm{~g}$ sample, cetane number 86.6 and pour point of $-18^{\circ} \mathrm{C}$.
\end{abstract}

Key words: Sterculia oil, branched fatty ester, biodiesel, cetane number, pour point.

\section{INTRODUCTION}

Fatty acid methyl esters, known as "biodiesel", are a product of the transesterification process of vegetable oils with methanol. Biodiesel is getting much attention from various countries around the world as one form of renewable energy in the liquid phase to be used as fuel in diesel engines. Feedstock is used for biodiesel production in several countries, depending on the availability of vegetable oils at the local country. In Europe, the feedstock for biodiesel are rapeseed oil (RSO) and sunflower oil (SFO), soybean oil (SBO) is used in USA, Malaysia and Indonesia using palm oil (PMO). In the last five years, several countries including Indonesia have begun to grow non-food crops such as Jatropha, kusambi, nyamplung and marine algae into feedstock for biodiesel (Soerawijaya, 2003).
The chemical composition of vegetable oils used as raw material for biodiesel varies based on the source, and is generally a triglyceride composed of long straight chain fatty acids $\left(\mathrm{C}_{12}-\mathrm{C}_{18}\right)$ (Wang, 2007). The physical properties of biodiesel such as cetane number, pour point and viscosity, are strongly influenced by the carbon-chain length of the constituent fatty acids (Markley KS, 1961). Cetane number of biodiesel produced from vegetable oils that are of long straight chain fatty acids are generally above the cetane number of diesel fuel, but has a high pour point and flash point (Knothe et al., 2003). Lee et al. (1996), says that biodiesel is synthesized from a long straight chain fatty acids crystallized at lower temperatures, and crystallization was triggered by the high pour point. The high pour point of the resulting 
biodiesel for diesel engines that exist today (diesel engines designed for diesel fuel) must still be mixed with diesel fuel (for example, biodiesel programe of PT. Pertamina in Indonesia which has been known as B5 and B10). Before the use of biodiesel directly and securely, even in cold climates, an additive lowering pour point (pour point depressant) should be added. But the problem is that during this process, fuel additive is generally synthesized from petroleum (Suppes et al., 2001; Knothe et al., 2006).

Previous researchers have made efforts at problem solving weaknesses of biodiesel in particular to the high pour point. Wang (2007) conducted a study on the use of isopropyl ester as a solution to the high pour point of biodiesel, and Puche (2008) in patent EP1331260 using glycerol tri-acetate as a biodiesel additive for lowering the freezing point. Wang (2007) compared the methyl ester with isopropyl ester derivatives which yielded high oleic soybean oil and reported that the isopropyl ester derivatives in the form of soybean oil provides improved properties, that is, pour point $-18^{\circ} \mathrm{C}$, numbers Cetana 57.1 and the lowest calorific value of $16,566 \mathrm{Btu} / \mathrm{lb}$, whereas in the form of methyl ester tuangnya point is $0^{\circ} \mathrm{C}$, and the numbers 47.2 and Setana lowest calorific value is $16,100 \mathrm{Btu} / \mathrm{lb}$. Puche reported that glycerin triacetate effectively lower the freezing point of biodiesel from rapeseed oil, which was originally frozen dotted -7 to $-16^{\circ} \mathrm{C}$ for the mixing of $5 \%$ and $-17^{\circ} \mathrm{C}$ for $10 \%$ mixing.

Literature searches provide information that branched fatty acids or esters have branched pour point and low crystallization temperature. Lee et al. (1995) reported that the use of branched esters of oils or fats can lower the crystallization temperature. Branched ester can be obtained by reacting vegetable oils (glycerides) or fatty acids with branched chain alcohols such as isopropyl alcohol or isobutyl alcohol. Lee argued that the use of isopropyl alcohol as a reagent can lower the crystallization temperature to $11.2^{\circ} \mathrm{C}$ than when using methanol. Kinsman (1979), states that the branched fatty acids have properties very different from a straight chain fatty acids. The position and number of branches is a factor that most determine the difference in physical properties of branched fatty acids than ordinary fatty acids. According to Kinsman's research the pour point of iso-stearic acid esters are generally much lower than stearic and oleic acid ester.

As described above, the branched fatty acids or esters have a low pour point and it is predicted that if the branched ester is used as an additive biodiesel it will produce a biodiesel blend with a lower pouring point, so its use is not only limited to $5 \%$ but can be more than that or even $100 \%$. Some types of vegetable oils in Indonesia can be used as raw material to synthesize the branched ester. Soerawijaya (2002) reported that one type of vegetable oils that is possibly used for branching on the carbon chain is Sterculia oil obtained from seed nuclei Sterculia (Sterculia foetida L.). The core seed Sterculia contains 44 to $54 \%$ oil by weight, with the largest fatty acid composition being as much as 69 to $73 \%$ sterculic acid with molecular formula $\mathrm{C}_{19} \mathrm{H}_{34} \mathrm{O}_{2}$ which have cyclopropenil group on the carbon chain chain (Knothe et al., 2005). This cluster can trigger a polymerization reaction at room temperature (Wilson et al., 1961). Kai (1982), Zarins et al. (1982), and Nunn (1952), stated that the cyclopropenil group can be converted into methyl branching without cutting the carbon chains that exist. Based on the above description, it is possible to produce esters of branched fatty acid from sterculia oil that will produce special properties esters that can be used as an additive in biodiesel.

This article describes the study on the process flow that can be taken to make the branched fatty esters from Sterculia oils, and branched fatty esters properties.

\section{MATERIALS AND METHODS}

Sterculia seeds were obtained from Sumbawa, West Nusa Tenggara, Indonesia. Methanol, isopropanol, Sodium Hydroxide, nhexane, and the chemicals used in this study were obtained from the PT. Intraco.

\section{Extraction}

The vegetable oil used in this study was Sterculia oil. It was obtained through Sterculia seed extraction. Extraction was done by the method of extraction stages with a total time of $6 \mathrm{~h}$. The numbers of extraction stages are three stages, and each phase lasts for $2 \mathrm{~h}$. Extraction procedure described is as follows: Sterculia seed nuclei are separated from their shells, then smoothed. Sterculia seed nuclei that have been mashed weighed $250 \mathrm{~g}$ and put in an extractor to be extracted by using n-hexane as much as $1250 \mathrm{ml}$. Extraction process of stage one was held for $2 \mathrm{~h}$ by stirring for $1 \mathrm{~min}$ for each time interval of $10 \mathrm{~min}$. The results obtained in the first phase were filtered to obtain extracts and rafinat. The oil obtained in the first stage was separated from the solvent by evaporation in rotavapour, then accommodated in the container. Extraction of the second and third stage was done by adding rafinat of the first phase with $\mathrm{n}$-hexane $1250 \mathrm{~mL}$. The oil obtained from the extraction stage one, two and three were combined and then weighed. By using gas chromatography- mass spectrometry (GC-MS) the oil and some physical properties of the acid number, saponification number and iodine number was later analyzed, according to Indonesian National Standard procedure.

\section{First transesterification}

Transesterification took place in a stirred tank reactor at a temperature of $50^{\circ} \mathrm{C}$ in $3 \mathrm{~h}$ and $\mathrm{N}_{2}$ atmosphere, by a stirring speed of 350 to $500 \mathrm{rpm}$. Before transesterification took place, free fatty acids in the Sterculia oil by the process of saponification advanced by using a solution of $1 \% \mathrm{KOH}$ in distilled water. Transesterification of Sterculia oil with methanol occurred by using sodium methoxide 


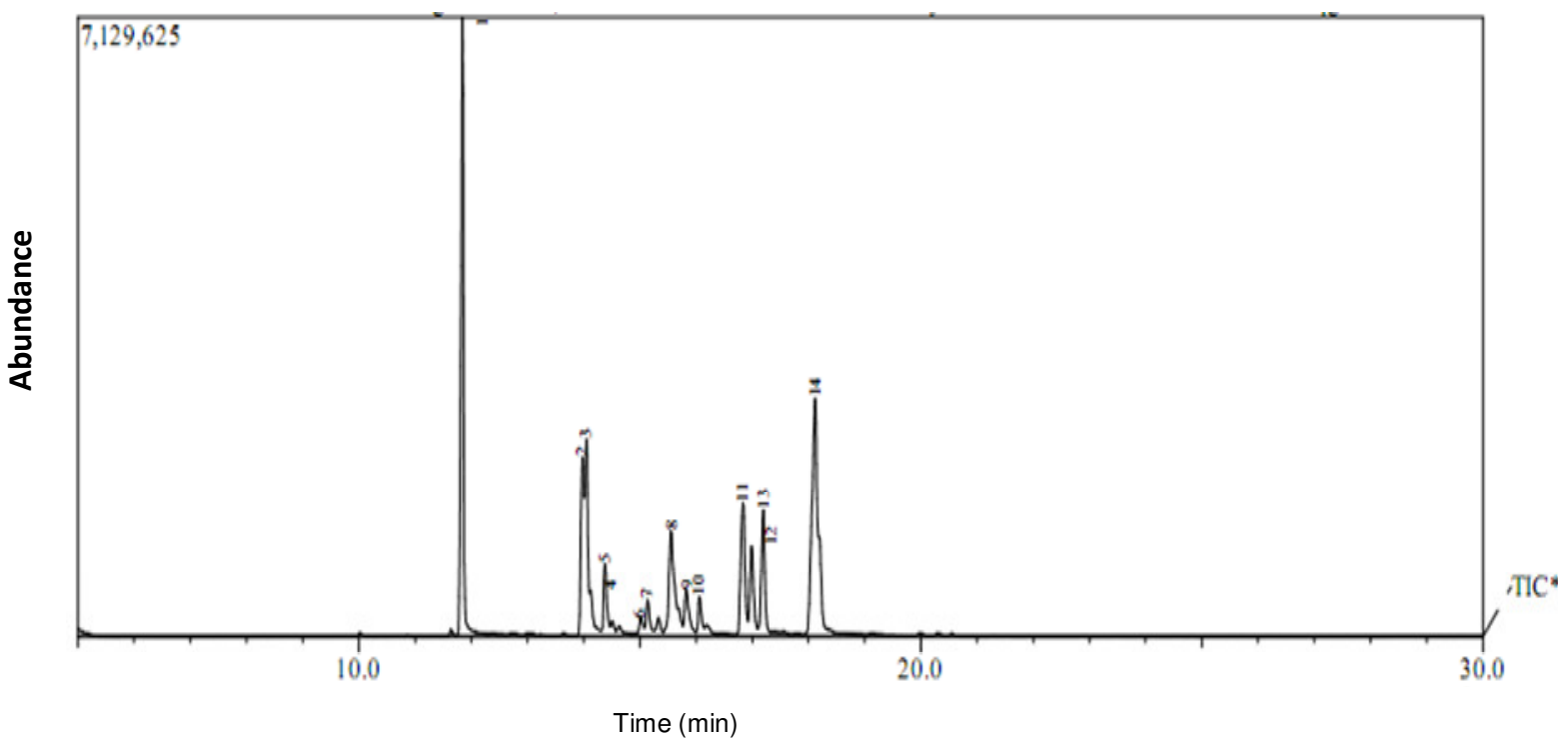

Figure 1. GC chromatogram of Sterculia oil.

catalyst (weight ratio of oil to the volume of methanol is 1: 5.6 and catalysts used as much as $0.014 \%$ by weight of oil). Before the reaction process, the reactor flowed into the nitrogen gas to remove the presence of oxygen. Pressure from the nitrogen gas that flows into the reactor was maintained at 0.5 to 0.7 bar. After the reaction lasted for $3 \mathrm{~h}$, the reaction product was extracted for $2 \mathrm{~h}$ using $\mathrm{n}$ hexane. The extract obtained was washed with distilled water and then dried. Methyl esters were separated from n-hexane in a rotavapor operated at $40^{\circ} \mathrm{C}$. Transesterification products were analyzed using GC-MS. Acid number, saponification number, and iodine number was determined by the Indonesian National Standard procedure.

\section{Hydrogenation}

$225 \mathrm{~g}$ methyl ester dissolved in $450 \mathrm{~mL}$ ethanol was added to $0.25 \%$ catalyst by weight 5 to $10 \% \mathrm{Pd}^{-\mathrm{Cl}_{2}}$ and reacted with hydrogen at 30 to $32^{\circ} \mathrm{C}$ for $6 \mathrm{~h}$. The results obtained after the hydrogenation reaction is separated from the catalyst and ethanol.

\section{Second transesterification}

Second transesterification was carried out to convert the methyl ester to isopropyl ester. Transesterification took place in a stirred tank reactor at a temperature of $30^{\circ} \mathrm{C}$, for $3 \mathrm{~h}$ at atmospheric pressure. Comparison of the reactants is as follows: $1 \mathrm{~g}$ of methyl ester compared with $20 \mathrm{~mL}$ of isopropanol, the catalyst used is sodium isopropoxide. After $3 \mathrm{~h}$ of the reaction the reaction product was neutralized with acetic acid and isopropyl ester was subsequently extracted for $2 \mathrm{~h}$ using $\mathrm{n}$-hexane. The extract obtained was washed with a solution of sodium bicarbonate $5 \%$ (w / v). Transesterification product was analyzed using GC-MS and analyzed acid number, saponification number, iodine number, viscosity, and the cetane number was by the Indonesian National Standard procedure.

\section{RESULTS AND DISCUSSION}

\section{Extraction}

Sterculia oil extraction process that was conducted in this study was a gradual process of extraction (multistage extraction). The obtained average Sterculia oils in weight percent in this study was $32.7 \%\left(30^{\circ} \mathrm{C}\right), 36.96 \%\left(45^{\circ} \mathrm{C}\right)$, and $38.64\left(60^{\circ} \mathrm{C}\right)$. Temperature greatly affects the resulting product. The biggest acquisition is obtained at $60^{\circ} \mathrm{C}$ which is $38.64 \%(\mathrm{w} / \mathrm{w})$, however it was obtained as dark oil, due to the oxidation of the oil. It can also be confirmed through the analysis of physical properties using Indonesian National Standard Procedure, which have been obtained as very high acid number of 15.7 $\mathrm{mgKOH} / \mathrm{g}$. Whereas at 30 and $45^{\circ} \mathrm{C}$ respectively $1.5 \mathrm{mg}$ $\mathrm{KOH} / \mathrm{g}$ and $8.3 \mathrm{mg} \mathrm{KOH} / \mathrm{g}$, saponification numbers in $\mathrm{mg}$ $\mathrm{KOH} / \mathrm{g}$ obtained was $180.52\left(30^{\circ} \mathrm{C}\right), 186.21\left(45^{\circ} \mathrm{C}\right)$ and $189.72\left(60^{\circ} \mathrm{C}\right)$ and iodine number in iodine $\mathrm{g} / 100 \mathrm{~g}$ samples obtained was $70.99\left(30^{\circ} \mathrm{C}\right), 69.29\left(45^{\circ} \mathrm{C}\right)$ and $66.62\left(60^{\circ} \mathrm{C}\right)$.

The results of GC-MS analysis, showed that Sterculia oil contains fatty acids that have cyclopropenil groups on the carbon chain. These results can be confirmed through data chromatogram and mass spectrum in Figures 1 to 3 .

In Figure 1, the presence of compounds that have cyclopropenil groups in oil extraction shows results that were indicated by the peak $6,7,8,9,11$, and 12 . The mass spectrum for sterculic acid as molecule target in the oil is shown in Figures 2 and 3.

Mass spectra data of target molecules in Figure 2, have 


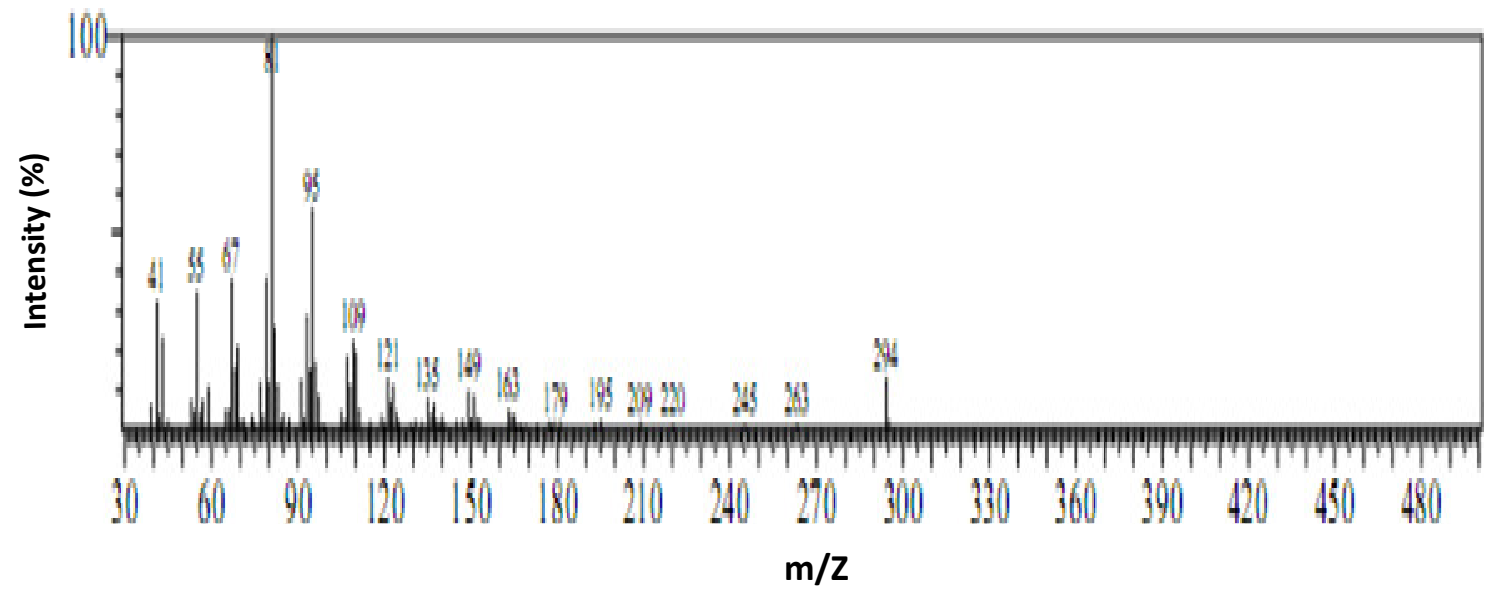

Figure 2. MS data for molecule target.

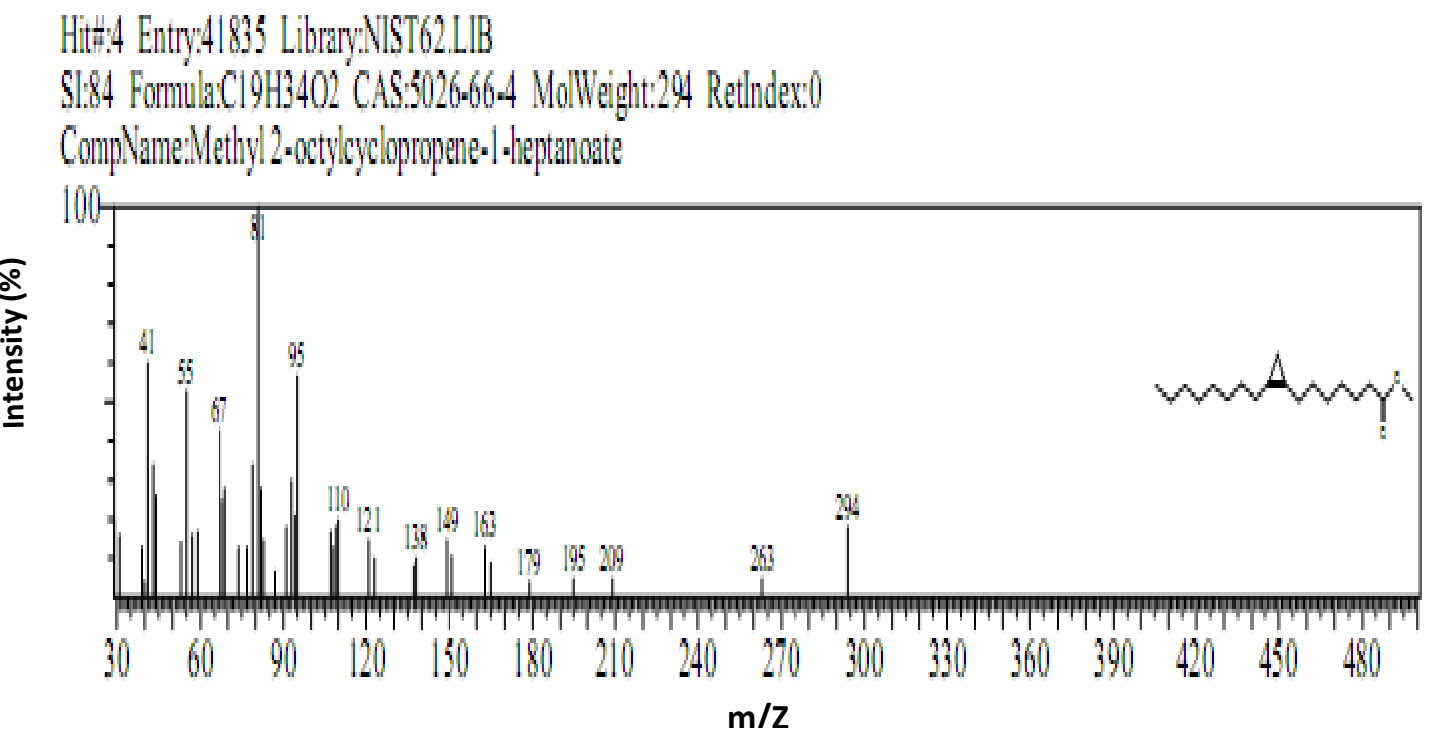

Figure 3. MS data standard for sterculic acid.

a pattern or similarity with the spectral data of molecular mass standards of sterculic acid as in Figure 3, which indicates the presence of the compound $\mathrm{C}_{19} \mathrm{H}_{34} \mathrm{O}_{2}$ having a molecular weight of $294 \mathrm{~g} / \mathrm{mol}$.

\section{First transesterification}

The rate of methyl esters produced in this study is about $60.20 \mathrm{~s} /$ day $(95.96 \%)$. Products of the transesterification process - acid number, saponification number and iodine number was analyzed. The results of analysis obtained revealed an average acid number $7.825 \mathrm{mg} \mathrm{KOH} / \mathrm{g}$, saponification number $188.85 \mathrm{mg} \mathrm{KOH} / \mathrm{g}$, and iodine number $26.94 \mathrm{~g} \mathrm{I} / 100 \mathrm{~g}$ sample. When compared with the physical properties of Sterculia oil, there was a difference in acid number, saponification number and iodine number. Furthermore, there was analysis of transesterification products using GC-MS. The results of the analysis are shown in Figure 4.

GC chromatogram of the Sterculia oil methyl ester derivatives showed the same pattern with the GC chromatogram of the Sterculia oil. Target compounds in the chromatogram were shown by peak 6 . Mass 


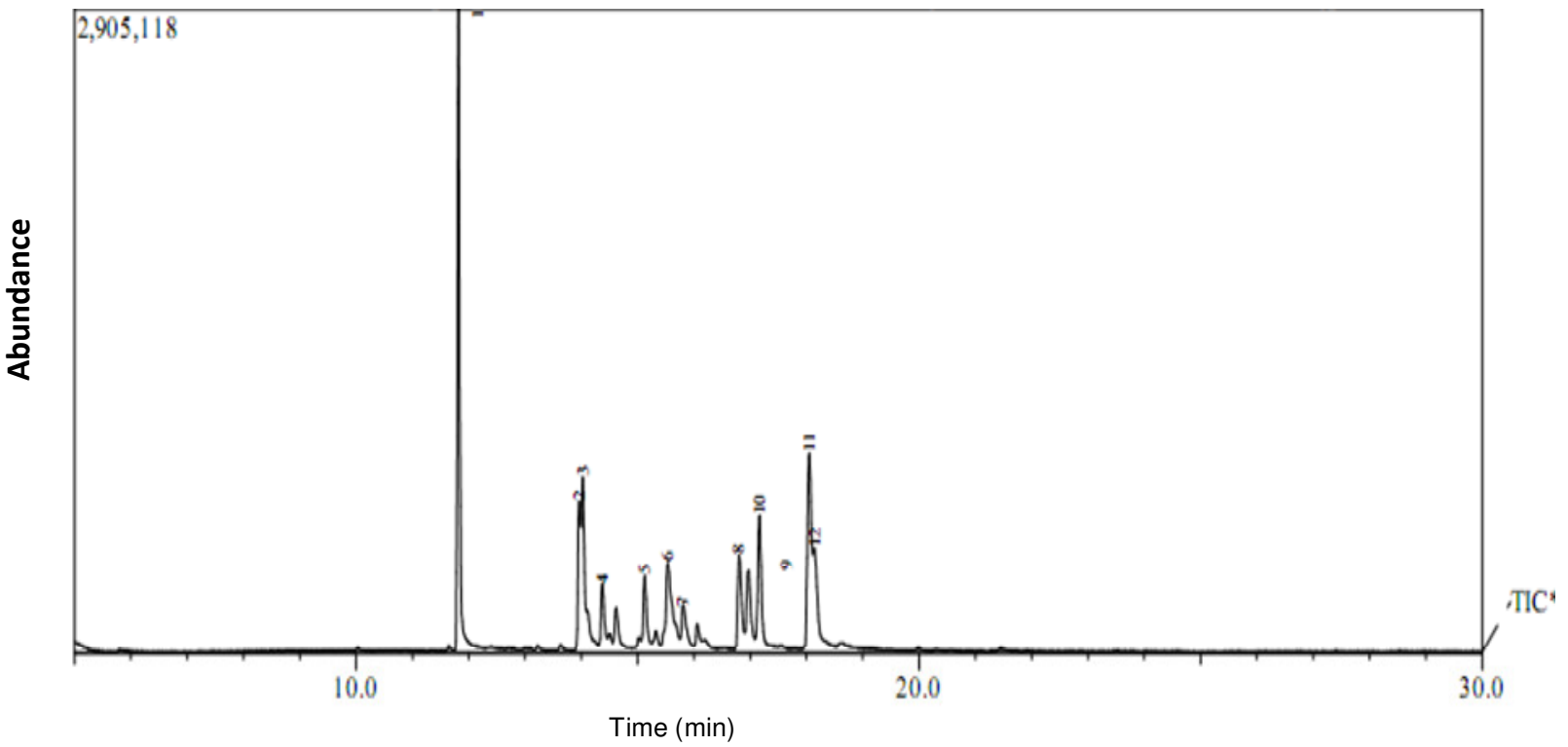

Figure 4. Chromatogram of methyl ester Sterculia oil derivatives.

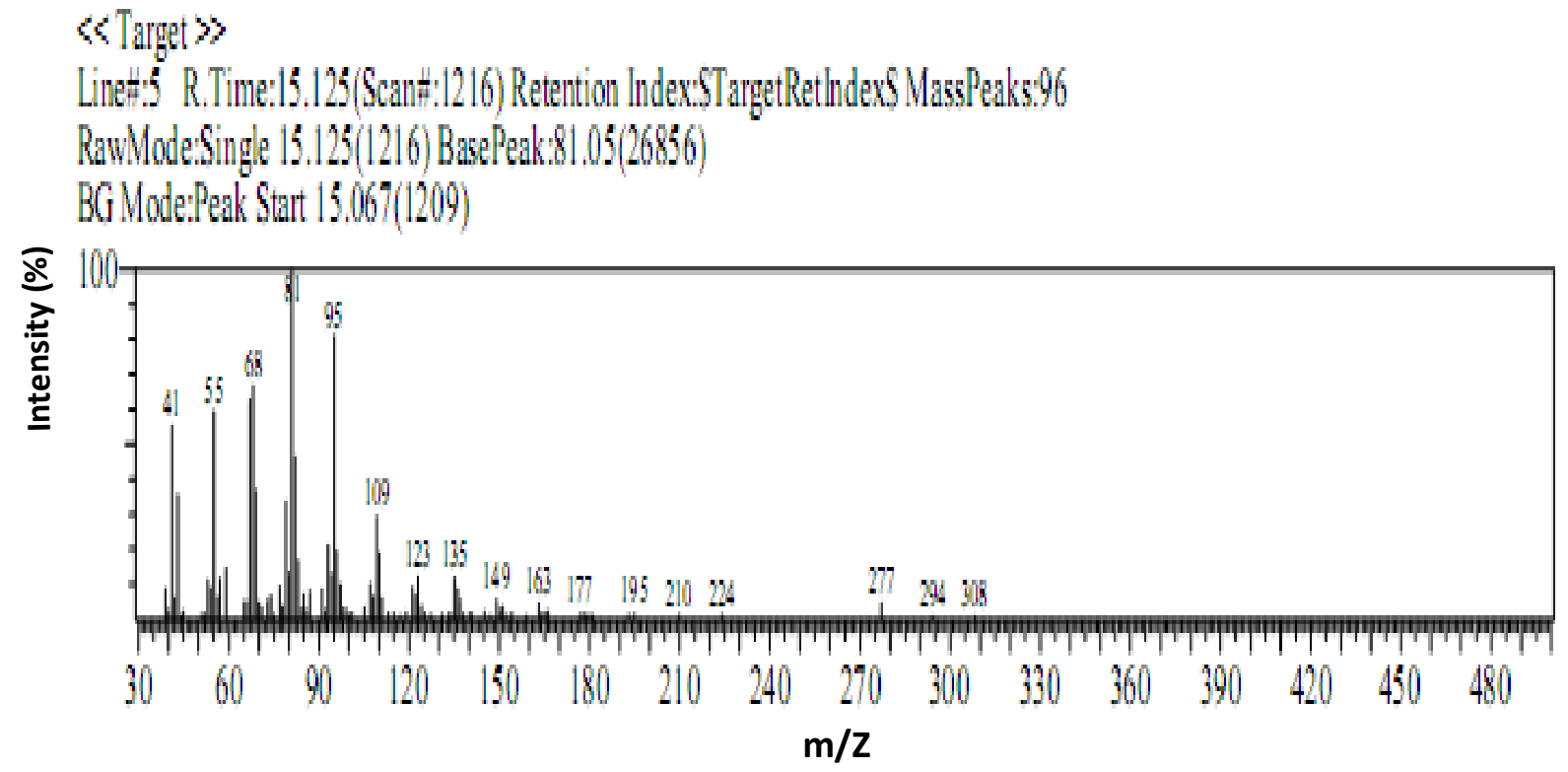

Figure 5. MS data for methyl sterculate target.

spectrum for the target molecules in the methyl ester is shown in Figure 5 and the standard molecule in Figure 6. Mass spectra data of target molecules in Figure 5 is a derivative product of sterculic acid $\left(\mathrm{C}_{19} \mathrm{H}_{34} \mathrm{O}_{2}\right)$, which has added a methyl group from the process of transesterification with methanol so that it becomes methyl sterculic $\left(\mathrm{C}_{20} \mathrm{H}_{36} \mathrm{O}_{2}\right)$ with molecular weight of 308 $\mathrm{g} / \mathrm{mol}$. The mass spectrum of the target molecule has a pattern or similarity with standard molecular mass spectrum data for the molecules in standard data Library Wiley229.Lib as in Figure 6, which shows the presence of compounds with a molecular weight of $308 \mathrm{~g} / \mathrm{mol}$ and 


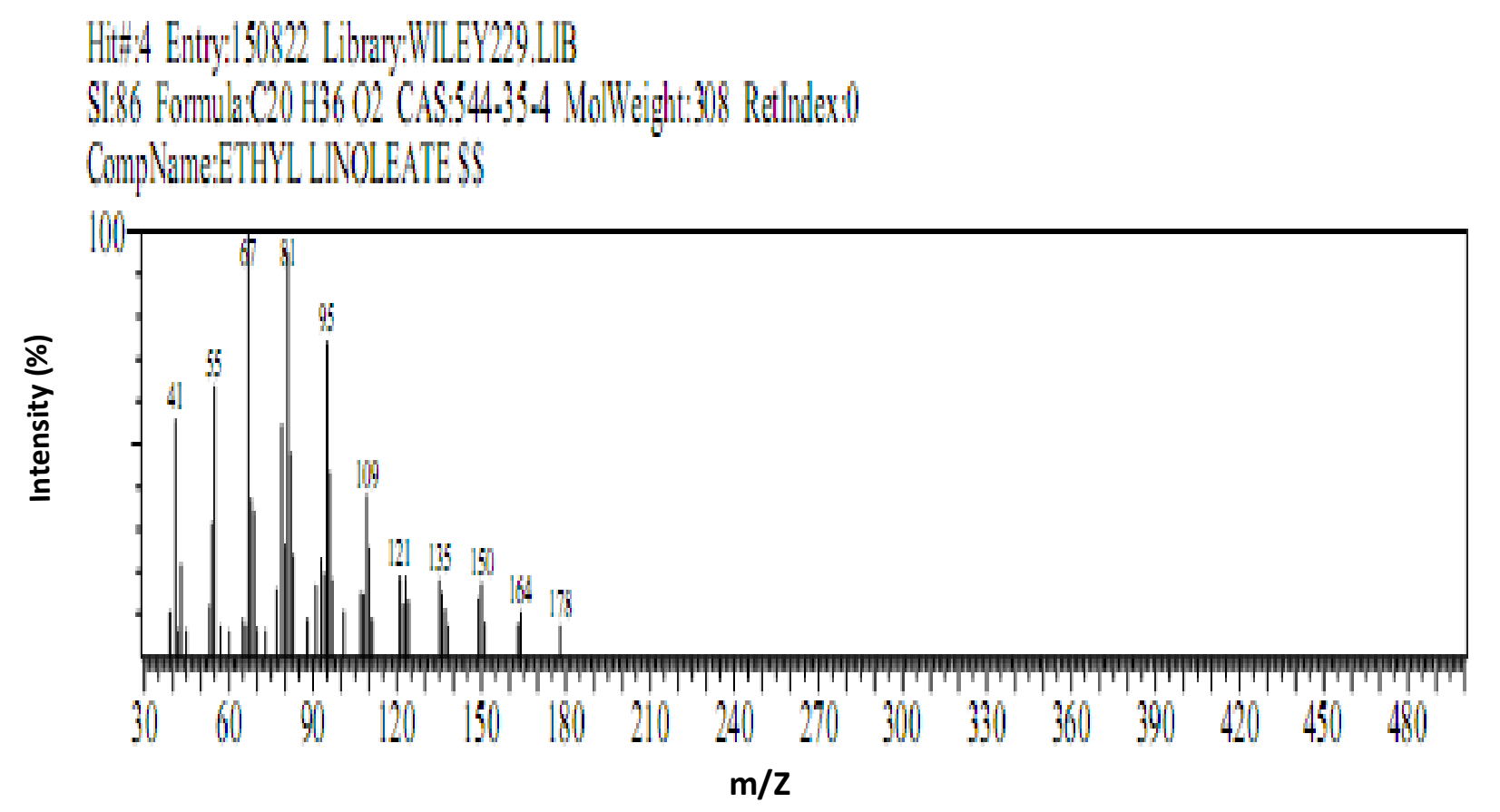

Figure 6. Standard MS data for methyl sterculate.

molecular formula $\mathrm{C}_{20} \mathrm{H}_{36} \mathrm{O}_{2}$.

\section{Hydrogenation}

Hydrogenation is an addition reaction of molecular hydrogen to were two or three bond are held in the presence of a catalyst. The catalyst used in this process is platinum, nickel, and palladium (Zarins et al., 1970). Several variables that affect the rate of hydrogenation reaction are temperature, hydrogen pressure, purity of reactants, catalyst activity and the level of acidity or alkalinity of the reaction medium. The rate of the hydrogenation stage is expressed in percentage by weight and is in the range 72.52 to $76.40 \%$. Further hydrogenation products (hydrogenated methyl ester) are obtained, and the iodine number was analyzed. From the analysis of iodine numbers it can be seen that a decrease in iodine number of the methyl ester before Sterculia oil ranges from 66.62 to $70.92 \mathrm{~g}$ iod/100 sample been from 16.06 to $16.96 \mathrm{~g}$ iod/100 samples after hydrogenation. Based on the analysis it was found that the hydrogenation process of methyl ester derived from sterculia oil which $10 \% \mathrm{Pd}-\mathrm{Cl}$ as catalyst in ethanol solvent at room temperature and reaction time of $6 \mathrm{~h}$, can convert cyclopropenyl group into a methyl branching in the carbon chain fatty acid. Some previous researchers namely Kai (1982), Walsh (2005), and Daniel et al. (2008) stated that the process of partial hydrogenation is carried out on fatty acids or methyl ester-containing group cyclopropenil rearrangement will result in a branching methyl group which then saturate double bond on the results of the rearrangement. The product of the hydrogenation process further transesterified with isopropanol produce molecules that $\mathrm{C}_{22} \mathrm{H}_{44} \mathrm{O}_{2}$ with 340 $\mathrm{g} / \mathrm{mol}$ molecular weight, as described in the discussion of transesterification with isopropanol.

\section{Second transesterification}

Acquisition rate is expressed as weight percent on a transesterification reaction with isopropanol in the range 37.96 to $50.75 \%$ sd. The reaction then characterized to determine physical properties of the resulting branched ester. Characterization results are presented in Table 1.

From Table 1 it is shown that branched ester transesterification with isopropanol results have a low pour point that is $-18^{\circ} \mathrm{C}$. Methyl esters such as methyl ester from palm oil, has a pour point of $16^{\circ} \mathrm{C}$ when compared with the pour point of straight-chain and the methyl ester of soybean oil that has a pour point of $-2^{\circ} \mathrm{C}$; it is apparent that the pour point branched ester produced is much lower. This supports the theory and the results of previous studies by the researchers that the pour point branched esters is much lower than the pour point equivalent straight-chain esters (Knothe et al., 2004). 
Table 1. Physical properties of the branched ester transesterification with isopropanol.

\begin{tabular}{clc}
\hline No. & Properties & Value \\
\hline 1. & Specific gravity & 0.870 \\
2. & lodine value $(\mathrm{g}$ iod $/ 100 \mathrm{~g}$ sample) & 16.25 \\
3. & Cetane number & 86.6 \\
4. & Cinematic viscosity, $40^{\circ} \mathrm{C}(\mathrm{cSt})$ & 5.907 \\
5. & Pour point $\left({ }^{\circ} \mathrm{C}\right)$ & -18 \\
\hline
\end{tabular}

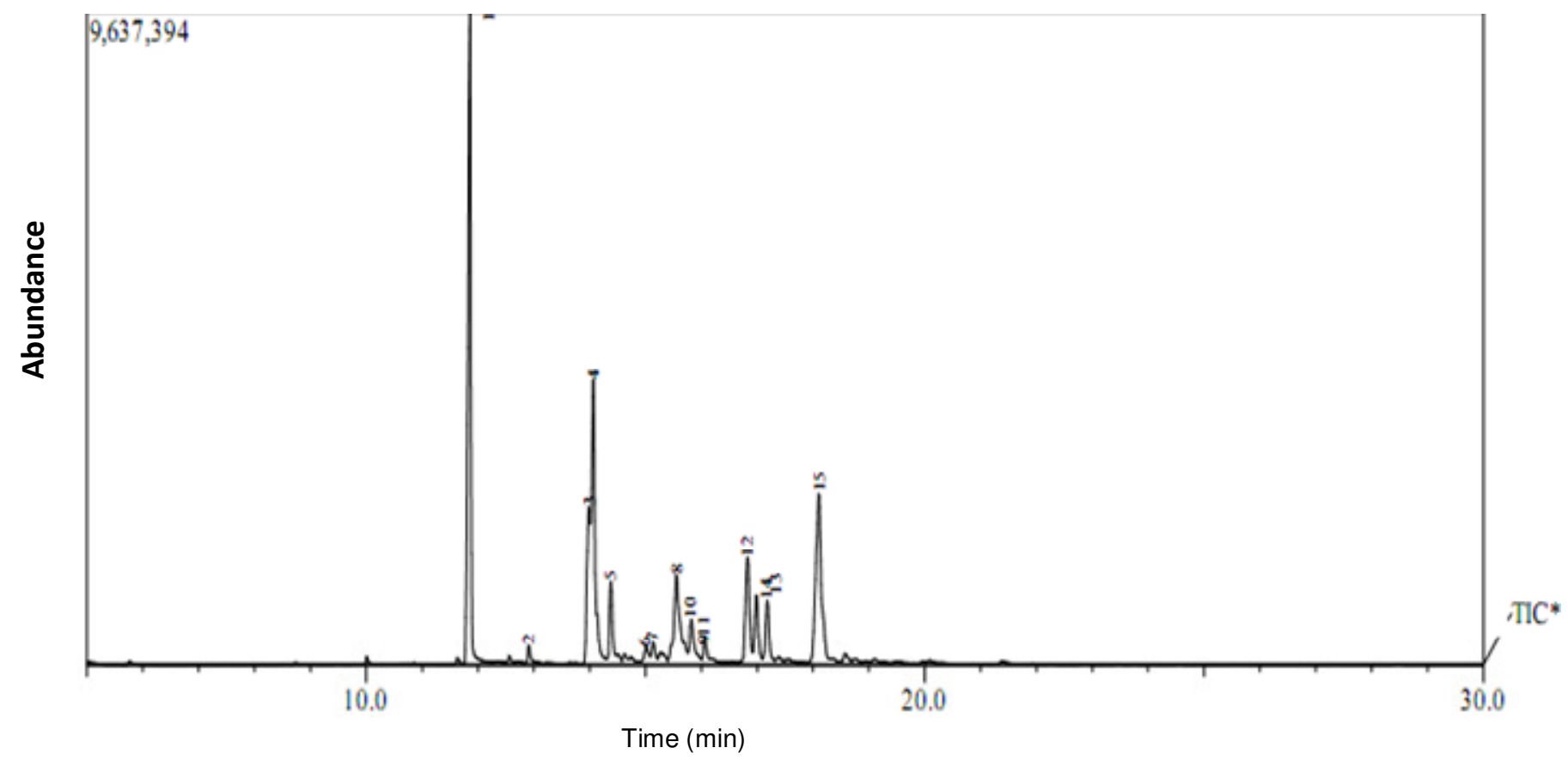

Figure 7. GC chromatogram results for transesterification with isopropanol.

GC-MS analysis results are expressed in the chromatogram and the mass spectrum for second transesterification product is presented in Figures 7 to 9 .

The existence of the product compound transesterification with isopropanol in Figure 7 is shown by peak 4 . Figures 8 and 9 showed a mass spectrum data for the target molecule results transesterification with isopropanol and standard molecular mass spectral data library Wiley229.Lib.

Based on data from the standard mass spectrum Library Wiley229.Lib as shown in Figure 9, it is noted that the target molecule in Figure 8 is a molecular compound of behenic acid $\mathrm{C}_{22} \mathrm{H}_{44} \mathrm{O}_{2}$ of molecular weight $340 \mathrm{~g} / \mathrm{mol}$.

Transesterification with isopropanol results in this study is not a pure compound but a mixture of isopropyl ester of hydrogenated methyl ester derivative of Sterculia oil that will be used as fuel. Other branched compounds contained in the mixture are of isopropyl palmitate, oleic and stearic acid. The presence of these compounds affect the physical properties of branched esters were analyzed in this study.

\section{Conclusion}

Based on these results, it can be concluded that (1) Sterculia oil can be used as raw material for the synthesis of branched fatty esters (2) characteristics of branched fatty esters obtained in this study are the specific gravity $\left(40^{\circ} \mathrm{C}\right) 0.870$, kinematic viscosity $\left(40^{\circ} \mathrm{C}\right) 5.907 \mathrm{cSt}$, iodine number $16.25 \mathrm{~g}$ iod $/ 100 \mathrm{~g}$ sample, 86.6 Cetana numbers, and pour point of $-18^{\circ} \mathrm{C}$. Branched fatty acid ester obtained have molecular formula of $\mathrm{C}_{22} \mathrm{H}_{44} \mathrm{O}_{2}$, with molecular weight of $340 \mathrm{~g} / \mathrm{mol}$. 


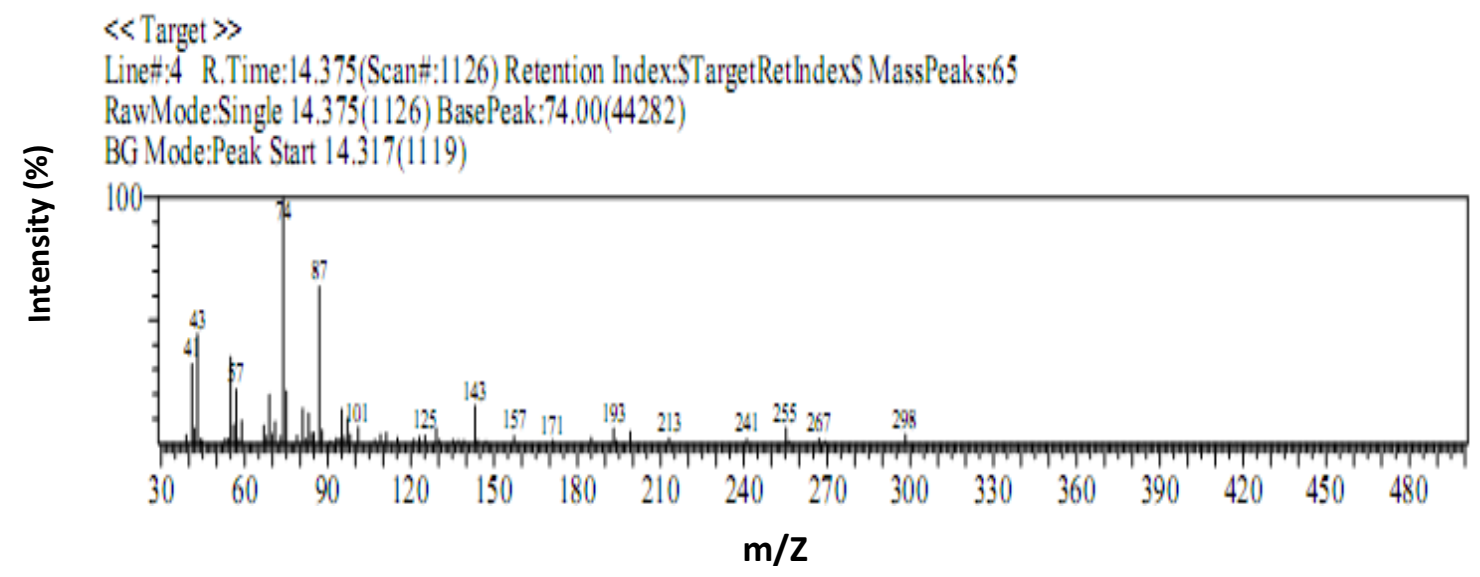

Figure 8. MS data target for $\mathrm{C}_{22} \mathrm{H}_{44} \mathrm{O}_{2}$.

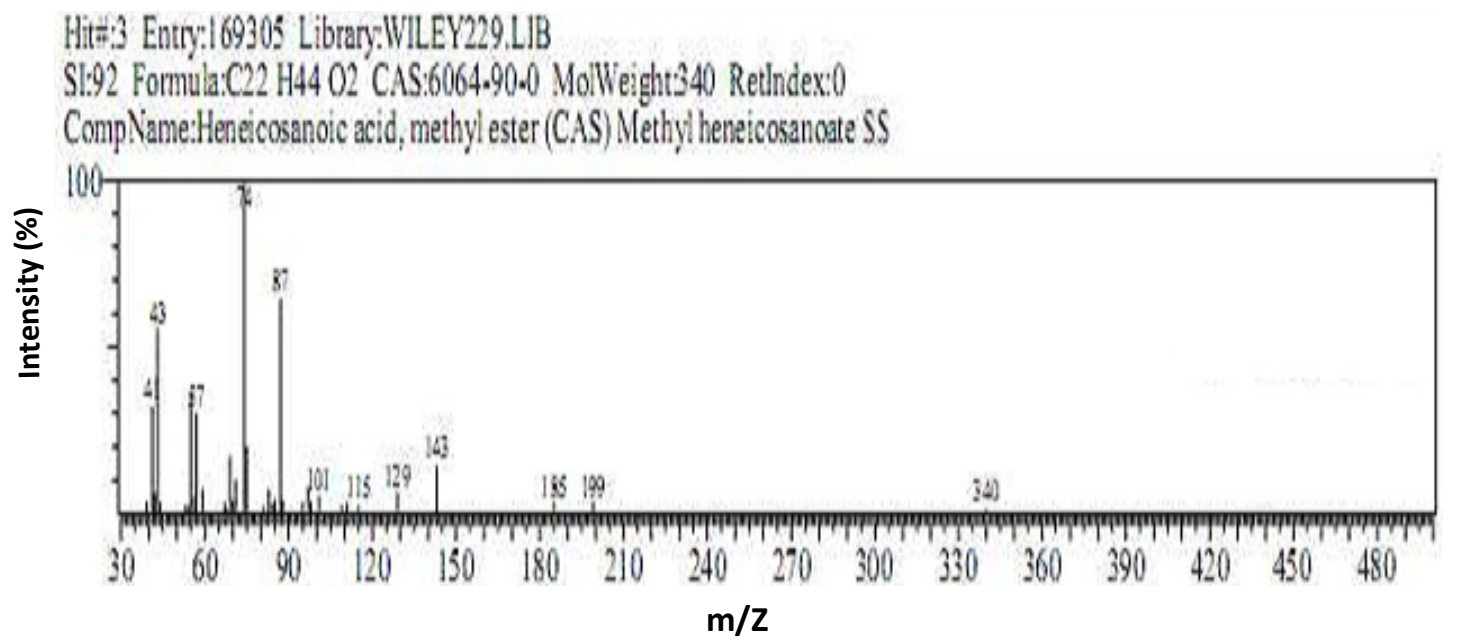

Figure 9. Standard $\mathrm{MS}$ data for $\mathrm{C}_{22} \mathrm{H}_{44} \mathrm{O}_{2}$.

\section{ACKNOWLEDGMENTS}

Thanks to director of Research and Public Service Directorate General of Higher Education, Ministry of Education and Culture of the Republic of Indonesia, for research funding through the National Strategic Research Grant in 2012.

\section{REFERENCES}

Daniel L, Van De Bovenkamp HH, Buntara T, Maemunah S, Kraaj G, Makertihartha IGBN, Manurung R, Heeres HJ (2008). Chemical Modification of Sterculia Foetida L. Oil to Highly Branched Ester Derivatives. University of Groningen, The Netherlands.

Kai $Y$ (1982). Production of Branched-Chain Fatty Acids from Sterculia Oil. JAOCS 59(7):300-305.

Kinsman DV (1979). Isostearic and Other Branched Acids". JAOCS
56(11):823A- 827A.

Knothe G, Krahl J, Gerpen JV (2005). "The Biodiesel Handbook” AOCS Press, Campaign, Ilinois.

Knothe G, Matheaus AC, Ryan TW (2003). Cetane numbers of branched and straight-chain fatty ester determined in an ignition quality tester. Fuel 82:971-975.

Knothe G, Sharp CA, Ryan TW (2006). Exhaust Emissions of Biodiesel, Petrodiesel, Neat Methyl Esters, and Alkanes in a New Technology Engine. Energy Fuels 20:403-408.

Knothe G (2008). Designer Biodiesel: Optimizing Fatty Ester Composition to Improve Fuel Properties. Energy Fuels 22(2):13581364.

Lee I, Johnson LA, Hammond EG (1995). Use of Branched-Chain Esters to reduce the Crystallization Temperature of Biodiesel. JAOCS 72(10): 1155-1160.

Lee I, Johnson LA, Hammond EG (1996b). Reducing the Crystallization Temperature of Biodiesel by Winterizing Methyl Soyate. JAOCS 73(5):631-636.

Markley KS (1961). Fatty Acids: Their Chemistry, Properties, Production and Uses. Interscience Publishers Inc. New York, Part I. 
Nunn JR (1952). The Structure ofSterculic Acid. J. Chem. Soc. 313318.

Puche D (2008). Use of Glycerine tri-asetat as Additive of Biodiesel Fuel Compositions. Patent EP1331260.

Suppes GJ, Goff M, Burkhart ML, Bockwinkel MK, Mason H, Botts JB, Heppert JA (2001). Multifunctional Diesel Fuel Additives from Triglycerides. Energy Fuels 15(1):151-157.

Wang PS (2007). Isoprophyl Esters as Solutions to Biodiesel Challenges. Dissertation of Degree of Doctor Philosophy Majoring in Biological and Agricultural Engineering in The College of Graduate Studies of IDAHO University.
Wilson TL, Smith JR, Mikolajczak KL (1961). Characterization of Cyclopropenoid Acids in Selected Seed Oils. JAOCS 38(12):1696699.

Zarins ZM, White JL, Willich RK, dan Feuge RO (1982). "Hidrogenation Cyclopropene Fatty Acids Occuring in Cottonseed Oil". J. Am. Oil Chemist' Soc. 59:511-515.

Zarins ZM, Willich RK, dan Feuge RO (1970). "Reaction of Cyclopropene Esters With Hidrogenation Catalysts". J. Am. Oil Chemist' Soc. 47:215-218. 